\title{
TLR7/9 antagonist reduces HIV-1-induced immune activation
}

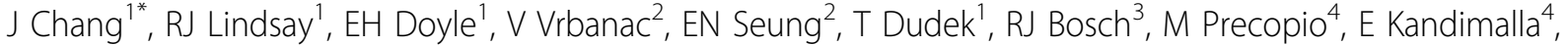 \\ A Tager ${ }^{2}$, M Altfeld $^{1}$
}

From AIDS Vaccine 2012

Boston, MA, USA. 9-12 September 2012

\section{Background}

$\mathrm{T}$ cell immune activation is a strong predictor of HIV-1 disease progression and HIV-1 transmission, and IFNalpha production following TLR7 stimulation has been associated with elevated $\mathrm{CD} 8^{+} \mathrm{T}$ cell activation (Meier et al., Nat Med 2009). We therefore hypothesized that modulation of TLR7 stimulation could be used to manipulate IFN-alpha production and subsequently reduce HIV1-associated immune activation. TLR7/9-specific antagonists developed for treatment of auto-immune diseases were used in vitro and in vivo in a humanized mouse model.

\section{Methods}

Humanized BLT mice were generated by transplanting irradiated NOD $/ \mathrm{SCID} / \gamma \mathrm{c}^{-/-}$mice with human fetal thymus and injected with human hematopoietic stem cells isolated from matching liver tissue. Following reconstitution, cells were harvested from the mice to examine the effects of the antagonist in vitro. Humanized mice were also infected with HIV-1 and then either treated or untreated with TLR7/9 antagonist from Idera. T cell activation markers were examined pre-infection, following infection and during treatment with the antagonist. Additionally, responsiveness of DCs to TLR7/8 stimulation ex vivo following in vivo TLR7/9 antagonist treatment was assessed by intracellular cytokine staining.

\section{Results}

16-20 weeks after transplant, human DC, monocyte and $\mathrm{T}$ cell populations were detectable in the mice. Ex vivo stimulation with TLR7/8 induced cytokine production by humanized mice DCs and monocytes similar to those observed from human PBMCs and this was significantly blocked by in vitro treatment with the TLR7/9 antagonist $(\mathrm{P}<0.05)$. HIV-1 infection of humanized mice led to increased $\mathrm{T}$ cell immune activation marker CD38 on human $\mathrm{T}$ cells in vivo, and treatment of infected mice with the TLR7/9 antagonist led to a significant reduction in CD38 expression.

\section{Conclusion}

Treatment of HIV-1-infected humanized BLT mice with a TLR7/9 antagonist resulted in a significant reduction of HIV-1-associated immune activation. This may have important implications in reducing viral transmission associated with higher immune activation in HIV-1.

\section{Author details}

${ }^{1}$ Ragon Institute of MGH, MIT and Harvard, Boston, MA, USA. ${ }^{2}$ Massachusetts General Hospital, Boston, MA, USA. ${ }^{3}$ Harvard School of Public Health, Boston, MA, USA. ${ }^{4}$ Idera Pharmaceuticals Inc., Cambridge, MA, USA.

Published: 13 September 2012

doi:10.1186/1742-4690-9-S2-P172

Cite this article as: Chang et al:: TLR7/9 antagonist reduces HIV-1induced immune activation. Retrovirology 2012 9(Suppl 2):P172.

${ }^{1}$ Ragon Institute of MGH, MIT and Harvard, Boston, MA, USA

Full list of author information is available at the end of the article

(C) 2012 Chang et al; licensee BioMed Central Ltd. This is an Open Access article distributed under the terms of the Creative Commons 